\title{
IMPLANTAÇÃO DE PROGRAMAS E AÇÕES DE EDUCAÇÃO AMBIENTAL NO MUNICÍPIO DE SÃO FRANCISCO (PB)
}

\author{
Alan Gurgel Saraiva ${ }^{1}$ \\ Leonardo Vieira Soares ${ }^{2}$ \\ Ricardo Moreira Da Silva ${ }^{3}$
}

Resumo: O presente trabalho apresenta propostas de programas e ações de Educação Ambiental (EA) para serem implantados no município de São Francisco (PB). É preciso criar um grupo de trabalho responsável pela criação dos programas e pela execução das ações, onde a coordenação do grupo de trabalho será de responsabilidade da Secretária de Saúde e Meio Ambiente. Cada programa de Educação Ambiental proposto neste trabalho tem sua metodologia particular para ser implantado. No final, o resultado esperado é que as propostas dos programas e ações de educação ambiente sejam aceitas pela prefeitura de São Francisco e implantados junto com a população local promovendo, assim, desenvolvimento sustentável e uma qualidade vida melhor para população local.

Palavras-chave: Educação Ambiental; Programas; Ações; São Francisco.

1Universidade Federal da Paraíba. E-mail: alan.gurgel@outlook.com 2Universidade Federal da Paraíba. E-mail: Ivsoares@ct.ufpb.br

3Universidade Federal da Paraíba. E-mail: ricardomoreira0203@hotmail.com 


\section{Introdução}

No passado, o desenvolvimento era considerado apenas no contexto de crescimento econômico e crescimento do PIB, e, portanto, menos atenção foi dada às questões ambientais, sociais, culturais e em programas de desenvolvimento. Mas, gradualmente, foi se revelando, através do surgimento de questões ambientais, a fraqueza desse tipo de pensamento e a importância de prestar atenção às questões ambientais tornou-se mais significativa (ZIARI, et al., 2018).

Em 1972, na conferência de Estocolmo, surge a Educação Ambiental (EA) para resolver os problemas ambientais. Essa ciência estuda as relações do ser humano com a natureza e tem o objetivo de difundir conhecimentos sobre a relação do homem com o meio ambiente, auxiliando na resolução da problemática ambiental.

A importância da EA é que, além da difusão de conhecimentos em relação ao meio ambiente, ela promove cidadania às pessoas e causa mudanças de postura, hábitos e comportamento. A Educação Ambiental ensina as pessoas a pensarem e agirem tanto individual como coletivamente. Liefländer e Bogner (2016) realizaram um estudo e concluíram que o uso de conjuntos de atitudes ambientais para promover o conhecimento ambiental tem aumentado, mostrando a possibilidade de que as atitudes sociais podem mudar através da educação. Eles podem estar em uma relação recíproca com o conhecimento ambiental.

A EA é a ferramenta e o método mais eficaz para aumentar o conhecimento e a conscientização, de modo a lidar com os desafios futuros, especialmente no que diz respeito à proteção do meio ambiente (HEIDARI et al., 2015). Novo-Corti et al. (2018) também confirmam que a EA se revela uma ferramenta poderosa para gerar um comportamento verde entre os cidadãos.

Por esses motivos, é de suma importância investir na EA. Esta ferramenta pedagógica causa mudança na maneira de agir e pensar do indivíduo. Assim, coletivamente, o indivíduo vai trabalhar para alcançar uma sociedade sustentável em que ele e todas as pessoas ao seu redor possam usufruir de boa qualidade de vida. Para isto é fundamental que todos tenham acesso ao meio ambiente de boa qualidade que gera bem-estar social.

Post e Meng (2018) afirmam que a relação entre educação e ação ambiental tem influências familiares e contextuais sobre a escolaridade. Também há influências ambientais e econômicas nacionais sobre os valores e, em seguida, os efeitos diretos e indiretos da escolaridade e do contexto familiar têm influência sobre os comportamentos ambientais.

Devido à importância da EA, foi criada a Política Nacional de Educação Ambiental, Lei Federal $n^{\circ} 9.795$ de 1999 que determina que a EA seja ministrada em todos os níveis de ensino. Por isso, Chaves e Gaia (2014) colocam que a escola deve ser o lugar onde o aluno é sensibilizado por 
questões ambientais, para que fora dela o mesmo possa dar continuidade para as suas ações ambientais, e assim ir se formando um cidadão. A escola também deve contínua e permanentemente estar sensibilizando o professor tendo em vista que ele é o principal agente promotor na escola - através de projetos e cursos de capacitação.

O presente trabalho tem como objetivo propor programas e ações de EA para serem desenvolvidos no município de São Francisco, no estado da Paraíba. Assim, tem grande relevância, pois, promoverá o desenvolvimento socioambiental neste pequeno município da Paraíba que tem um IDH (Índice de Desenvolvimento Humano) de 0,58, segundo o censo do IBGE em 2010, muito abaixo do IDH nacional que é de 0,754 , segundo o relatório de Desenvolvimento Humano (RDH) do Programa das Nações Unidas Para Desenvolvimento (PNUD) divulgado em 2017.

\section{Material e métodos}

Para a formação do grupo de trabalho, que será responsável pela implementação dos programas e das ações, é importante destacar que cada programa terá a sua própria metodologia.

\section{Formação do grupo de trabalho}

O grupo de trabalho será formado por um represente de cada um dos seguintes coletivos: Secretaria de Saúde e Meio Ambiente, Secretaria de Infraestrutura, Urbana e Rural, Secretaria de Educação, agricultores, professores e diretores das escolas do município, comerciantes e empresários, catadores de matérias recicláveis e reutilizáveis, e representantes das indústrias da região.

Para selecionar os representantes de cada coletivo, a metodologia escolhida será a técnica "bola de neve" (Snowball Sampling). Ela consiste na aplicação de questionários que servirão de suporte para entrevistas semi dirigidas direcionadas para cada coletivo.

A técnica chamada "bola de neve" é uma metodologia qualitativa da sociologia, utilizada entre indivíduos que compartilham ou conhecem outras pessoas que possuem algumas características que são de interesse da pesquisa. O método é bem adequado para várias finalidades de pesquisa e é, particularmente, aplicável quando o foco do estudo está em um assunto delicado, e relacionado a um assunto relativamente privado (BIERNACKI; WALFORD, 1981).

O coordenador do grupo de trabalho será a Secretaria de Saúde e Meio Ambiente. As atividades desenvolvidas pelo grupo serão: avaliar o andamento dos programas, fazer planejamento, execução e divulgação dos programas. 


\section{Metodologia dos programas de Educação Ambiental}

Para compreender melhor sobre a obtenção de metas, em cada programa foi estabelecido três períodos de prazo com diferentes intervalos de tempo, a saber:

$>$ Curto prazo - período de 0 a 4 anos;

> Médio prazo - período entre 4 e 8 anos;

$>$ Longo prazo - período entre 8 e 20 anos.

É importante mencionar que para implantação destes programas, ações deverão ser realizadas. Estas ações podem ser contínuas ou se encaixar num prazo de tempo.

Segundo o Ministério do Meio Ambiente (2016), o conceito de objetivo é descrito como aquela situação que se visa alcançar, mediante a execução dos programas e a realização das ações previstas. Já a meta é uma tarefa traçada para alcançar os objetivos. É importante, sempre que for avaliar uma meta, comparar a situação atual com a linha de base (situação inicial). $O$ indicador, no que Ihe concerne, tem o objetivo de avaliar o programa durante sua execução para corrigir possíveis problemas.

Todas as propostas de EA neste trabalho têm o objetivo de serem programas permanentes no município de São Francisco. Por essa razão, segue abaixo a descrição da metodologia de cada programa.

\section{a) Coleta Seletiva}

Para implantação da coleta seletiva no município de São Francisco, o método utilizado é o mesmo recomendado pelo Ministério do Meio Ambiente para municípios com população inferior a 20 mil habitantes. O órgão ambiental do município ficará responsável por fechar um acordo com uma cooperativa de catadores para coleta seletiva. O esperado é que esse acordo envolva a compra de coletores para coleta seletiva, veículos adequados para coleta seletiva e dos equipamentos de proteção individual (EPIs).

A instalação do galpão de triagem e de dois pontos de entrega voluntária (PEVs) que serão feitos em pontos considerados estratégicos pela prefeitura do município será de responsabilidade da Secretaria de Infraestrutura Urbana e Rural. Optou-se por envolver as escolas e alunos na implantação dos programas para desenvolver conhecimentos ambientais nos estudantes. Braun e Dierkes (2017) afirmam que o baixo conhecimento ambiental dos alunos destaca a necessidade da promoção global da EA através de abordagens externas à escolástica, de modo a manifestar mudanças comportamentais sustentadas. 
A participação social num programa de coleta seletiva depende do perfil socioeconômico e cultural da população, com destaque para aspectos como grau de instrução e acesso à educação não formal. Neste sentido, a adequação do projeto à realidade local, a regularidade no funcionamento da logística implantada e a eficiência da estratégia de marketing para sensibilização e motivação da população são fundamentais (BRINGHENTI; GÜNTHER, 2011).

b) Reutilização, Reciclagem e Reaproveitamento de Resíduos Sólidos

O órgão ambiental do município será responsável por divulgar e organizar o evento junto com os comerciantes da região com o objetivo de comercializar roupas, calçados e produtos eletrônicos a preços baixos.

c) Logística reversa

O órgão municipal de meio ambiente será responsável pela criação de um acordo setorial com alguma empresa, instituto ou associação especializada em logística reversa de pilhas e baterias.

\section{d) Compostagem}

A metodologia deste programa é baseada no programa desenvolvido pela cidade de São Paulo em 2014, chamado de Composta São Paulo. Os alunos levarão a massa de resíduo orgânico de casa para as escolas do município, para que as escolas possam ensinar aos estudantes a fazer o processo de compostagem. As composteiras deste programa ficarão nas escolas para fins educativos. Cada escola do município terá sua própria composteira.

\section{Resultados}

Espera-se que os programas e as ações sejam aprovados. Abaixo segue os resultados esperados de cada programa:

a) Coleta Seletiva

A Implantação da coleta seletiva vai envolver as Secretarias de Infraestrutura Urbana e Rural, de Educação, de Saúde e Meio Ambiente, catadores de materiais recicláveis e de materiais reutilizáveis, professores e diretores das escolas, além de toda comunidade. A participação social e a divulgação da coleta seletiva são fundamentais para que os programas e ações deem certos. 
Bringhenti e Günther (2011) destacam fatores que motivam e dificultam a participação social em programas de coleta seleta. Como fatores motivadores indica-se o meio ambiente e a qualidade de vida associados à melhoria da limpeza urbana, a redução do perigo representado pela manipulação e disposição inadequada de RSU à população e ao pessoal que trabalha na limpeza urbana, a organização e a adequação da estrutura operacional implantada para dar suporte ao programa e a existência de ações continuadas de divulgação, mobilização e informação. Como fatores negativos, que dificultam a participação social num programa de coleta seletiva estão a falta de divulgação dos resultados da coleta seletiva, a acomodação e desinteresse da população, o nível cultural e de instrução do povo brasileiro e o descrédito relativo às ações oriundas do poder público e falta de espaço para armazenar resíduos recicláveis nas residências.

Neste sentido, o trabalho da Secretaria de Educação e dos professores será conscientizar os alunos sobre o que é, como funciona e a importância da coleta seletiva. Para isto, será realizada uma palestra mensal com a participação de toda comunidade a respeito do trabalho que a coleta seletiva vem desenvolvendo na comunidade e também a inclusão da temática no plano pedagógico das escolas.

Maddox et al. (2011) afirmam que a educação escolar baseada em resíduos pode por vezes ser vista pelas autoridades de coleta e descarte de resíduos sólidos como um complemento dispensável a outros métodos de aumentar a consciencialização dos resíduos.

A coleta de resíduos sólidos domiciliares (RSD) pode ser realizada porta a porta ou em ponto de entrega voluntário (PEV). Para o presente programa optou-se pela coleta porta a porta por ser uma forma de educar a população sobre a frequência da coleta do RSD como também do tempo de acondicionamento.

Como ações para implantação da coleta seletiva é recomendado adquirir veículo adequado para coleta seletiva e equipamentos de proteção individual (EPIs), a instalação de um galpão de triagem, a presença de coletores da coleta seletiva em locais que sejam considerados estratégicos, instalação de dois pontos de entrega voluntária para resíduos da construção e demolição (RCD) e materiais recicláveis.

A meta geral é que pelo menos $40 \%$ das residências do município seja atendido até o final do primeiro ano do programa e que até o terceiro ano do programa todas as residências do município sejam beneficiadas com a coleta seletiva. O nome do programa será "São Francisco Mais Limpa".

A implantação total da coleta seletiva requer um período de longo prazo por questões financeiras. Então, entende-se que um período de cerca de 10 anos seja suficiente para execução de todas as ações e a realização do programa. A Tabela 1 mostra o programa e as ações para implantação da coleta seletiva. 
Tabela 1 - Programa e Ações para coleta seleta.

\begin{tabular}{|c|c|c|c|c|c|c|}
\hline \multirow{2}{*}{$\frac{1^{\circ} \text { Passo }}{\text { Objetivos }}$} & \multirow{2}{*}{$\frac{2^{\circ} \text { Passo }}{\text { Programas e Ações }}$} & \multicolumn{3}{|c|}{$3^{\circ}$ Passo } & \multicolumn{2}{|r|}{$4^{\circ}$ Passo } \\
\hline & & Indicadores & Fonte da Informação & $\begin{array}{l}\text { Situação } \\
\text { Atual }\end{array}$ & Prazo & Metas \\
\hline \multirow{6}{*}{$\begin{array}{c}1 . \\
\text { Objetivo: } \\
\text { Implantar } \\
\text { coleta } \\
\text { seletiva } \\
\text { no } \\
\text { municipio. }\end{array}$} & $\begin{array}{l}\text { 1. Programa: "São } \\
\text { Francisco Mais Limpa". }\end{array}$ & $\begin{array}{l}\text { 1. Indicador Geral: Número } \\
\text { de domicílios atendidos pela } \\
\text { coleta seletiva dividido pelo } \\
\text { número total de domicílios } \\
\text { multiplicado por cem. }\end{array}$ & $\begin{array}{l}\text { Cadastro anual feito pela } \\
\text { Secretaria de Saúde e } \\
\text { Meio Ambiente dos } \\
\text { domicilios e ruas atendidos } \\
\text { pela coleta seletiva }\end{array}$ & $\begin{array}{l}\text { Nenhum } \\
\text { domicilio } \\
\text { atendido. }\end{array}$ & Curto & $\begin{array}{l}\text { 1. Meta Geral: } 40 \% \text { das } \\
\text { residências atendidas pela } \\
\text { coleta seletiva no primeiro } \\
\text { ano do programa. }\end{array}$ \\
\hline & $\begin{array}{l}\text { 1.1. Ação: conscientizar } \\
\text { a população sobre o } \\
\text { que é coleta seletiva, a } \\
\text { importância e como ela } \\
\text { funciona. }\end{array}$ & $\begin{array}{l}\text { 1.1. Indicador Específico: } \\
\text { Número de pessoas que tem } \\
\text { consciência sobre o que é } \\
\text { coleta seletiva e como se faz } \\
\text { a coleta seletiva }\end{array}$ & $\begin{array}{l}\text { Levantamento feito pela } \\
\text { Secretaria de Educação }\end{array}$ & $\begin{array}{l}\text { Sem } \\
\text { dados. }\end{array}$ & Contínuo & $\begin{array}{l}\text { 1.1. Meta específica: } \\
\text { Conscientizar toda } \\
\text { população sobre o que é } \\
\text { coleta seletiva e como se faz } \\
\text { a coleta seletiva antes da } \\
\text { implantação do programa. }\end{array}$ \\
\hline & $\begin{array}{l}\text { 1.2. Ação: Adquirir } \\
\text { veículo adequado para } \\
\text { coleta seletiva }\end{array}$ & $\begin{array}{l}\text { 1.2. Indicador Específico: } \\
\text { Número de veículos } \\
\text { adquiridos }\end{array}$ & $\begin{array}{l}\text { Dados anuais fornecidos } \\
\text { pela Secretaria de Saúde e } \\
\text { Meio Ambiente }\end{array}$ & $\begin{array}{l}\text { Um } \\
\text { veículo }\end{array}$ & Curto & $\begin{array}{l}\text { 1.2. Meta específica: } \\
\text { Adquirir mais um veículo até } \\
\text { o segundo ano de execução } \\
\text { do programa }\end{array}$ \\
\hline & $\begin{array}{l}\text { 1.3. Ação: Adquirir } \\
\text { equipamentos de } \\
\text { proteção individual } \\
\text { (EPIs) }\end{array}$ & $\begin{array}{l}\text { 1.3. Indicador Específico: } \\
\text { Número de EPIs adquiridos }\end{array}$ & $\begin{array}{l}\text { Dados anuais fornecidos } \\
\text { pela Secretaria de Saúde e } \\
\text { Meio Ambiente }\end{array}$ & $\begin{array}{l}\text { Sem } \\
\text { dados }\end{array}$ & Curto & $\begin{array}{l}\text { 1.4. Meta específica: } \\
\text { Adquirir equipamentos de } \\
\text { proteção individual (EPIs) } \\
\text { para todos catadores }\end{array}$ \\
\hline & $\begin{array}{l}\text { 1.4. Ação: instalar um } \\
\text { galpão de triagem }\end{array}$ & $\begin{array}{l}\text { 1.4. Indicador Específico: } \\
\text { Número de galpões de } \\
\text { triagem instalados }\end{array}$ & $\begin{array}{l}\text { Secretaria de } \\
\text { Infraestrutura, Urbana e } \\
\text { Rural } \\
\end{array}$ & $\begin{array}{l}\text { Nenhum } \\
\text { Galpão } \\
\text { Triagem }\end{array}$ & Longo & $\begin{array}{l}\text { 1.4. Meta específica: } \\
\text { Instalar um galpão de } \\
\text { triagem até o segundo ano }\end{array}$ \\
\hline & $\begin{array}{l}\text { 1.5. Ação: colocar } \\
\text { coletores de coleta } \\
\text { seletiva em locais que } \\
\text { sejam considerados } \\
\text { estratégicos }\end{array}$ & $\begin{array}{l}\text { 1.5. Indicador Específico: } \\
\text { Número de coletores de } \\
\text { coleta seletiva instalados no } \\
\text { município }\end{array}$ & $\begin{array}{l}\text { Dados anuais fornecidos } \\
\text { pela Secretaria de Saúde e } \\
\text { Meio Ambiente }\end{array}$ & $\begin{array}{l}\text { Nenhum } \\
\text { coletor } \\
\text { seletivo } \\
\text { instalado }\end{array}$ & Curto & $\begin{array}{l}\text { 1.5. Meta específica: } \\
\text { Instalar } 12 \text { coletores de } \\
\text { coleta nos colégios e pelo } \\
\text { município até a implantação } \\
\text { do programa }\end{array}$ \\
\hline
\end{tabular}

b) Reutilização, Reciclagem e Reaproveitamento de Resíduos Sólidos

Para criação de programas de Reutilização, Reciclagem e Reaproveitamento de Resíduos Sólidos, têm-se as sugestões de criar um brechó que estimule a reutilização de produtos coletados como roupas, calçados, eletrodomésticos e eletrônicos e fazer trabalhos, feiras de ciências e gincanas nas escolas para conscientizar e sensibilizar os alunos a respeito da importância da reutilização, reciclagem e reaproveitamento de resíduos sólidos.

Para o brechó, as ações que podem ser desenvolvidas são a promoção de um evento para comercializar os produtos em condições de uso a preços baixos. A Secretaria de Saúde e Meio Ambiente será a responsável por estas ações. Este programa será chamado de "Brechó para todos". O evento será realizado uma vez por ano e o objetivo é que este programa seja contínuo no município.

Além do programa "brechó para todos", ainda se pretende implantar ações de Educação Ambiental que conscientizem e sensibilizem a população sobre a importância da preservação do meio ambiente e a economia de energia que a reutilização, a reciclagem e o reaproveitamento de resíduos sólidos causam. Para este fim, as escolas vão desenvolver atividades propostas por Supakata et al. (2016) que promovam o conceito dos 3Rs (reduzir - reutilizar - reciclar): o jogo da caixa de leite dobrável, competição de 
separação de resíduos, competição de reciclagem, jogo de perguntas e desenho.

A Tabela 2 ilustra o programa e as ações para estimular a reutilização, reciclagem e reaproveitamento de resíduos sólidos. O programa "Brechó para todos" vai funcionar para auxiliar no programa de coleta seletiva no município de São Francisco.

Tabela 2: programa e as açôes para estimular a reutilizaçào, a reciclaggen e 0 reaproveitamento de residuos sólidos.

\begin{tabular}{|c|c|c|c|c|c|c|}
\hline \multirow{2}{*}{$\begin{array}{l}1^{0} \text { Passo } \\
\text { Objetivos }\end{array}$} & \multirow{2}{*}{\begin{tabular}{|l|}
$\chi$ Passo \\
Programas e Açes \\
\end{tabular}} & \multicolumn{3}{|l|}{$3^{0}$ Passo } & \multicolumn{2}{|l|}{$4^{\prime}$ Passo } \\
\hline & & Indicadores & $\begin{array}{l}\text { Fonte } \\
\text { Informaçào }\end{array}$ & $\begin{array}{l}\text { Situaçào } \\
\text { Atual }\end{array}$ & Prazo & Metas \\
\hline \multirow{4}{*}{$\begin{array}{l}\text { 2. Objetivos: } \\
\text { estimular a } \\
\text { reutilizarajo de } \\
\text { proditos } \\
\text { coletados como } \\
\text { roupas, } \\
\text { calçados, } \\
\text { eletrodoméstico } \\
\text { se eletrotricos. }\end{array}$} & $\begin{array}{l}\text { 2. Programa: "Brechó } \\
\text { para Todos" }\end{array}$ & $\begin{array}{l}\text { 2. Indicador Geral. } \\
\begin{array}{l}\text { Percentual } \\
\text { reaprovetamento anval }\end{array}\end{array}$ & \begin{tabular}{|l|} 
Registro realzado \\
pelos voluntanos
\end{tabular} & $\begin{array}{l}\text { Nenhum } \\
\text { produto } \\
\text { reaproveita } \\
\text { do }\end{array}$ & Curto & $\begin{array}{l}\text { 2. Meta Geral: } \\
\text { Reaproveitamento anual de } \\
\text { pelo menos OW\% dos } \\
\text { proditos coletados em } \\
\text { condipóes de uso }\end{array}$ \\
\hline & $\begin{array}{l}\text { 21. Açio: Promover o } \\
\text { evento " Brechó para } \\
\text { Todos" }\end{array}$ & $\begin{array}{l}\text { 2.1. Indicador Especifico: } \\
\text { Nümero de eventos } \\
\text { promovidos }\end{array}$ & 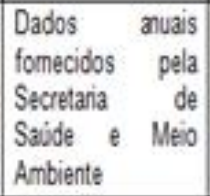 & & Continuo & $\begin{array}{l}\text { 21. Meta Especifica: } \\
\text { Promover erentos stmestrais } \\
\text { para esta finalidade }\end{array}$ \\
\hline & $\begin{array}{l}\text { 22. Açào: Comaccializar } \\
\text { os produtos em condipóes } \\
\text { de uso e a preços baixos }\end{array}$ & $\begin{array}{l}\text { 2.2. Indicador Especifico: } \\
\text { Percentual dos produtos } \\
\text { em condipóes de uso } \\
\text { comerciazados } \\
\text { anualmente }\end{array}$ & \begin{tabular}{|l|} 
Registro de venda \\
realizado relos \\
voluntános
\end{tabular} & $\begin{array}{l}\text { Nenhum } \\
\text { produto } \\
\text { comercializ } \\
\text { ado }\end{array}$ & Curto & $\begin{array}{l}\text { 22. Meta Espećfica: } \\
\text { Comercializar anualmante } \\
\text { pelo menos } 806 \text { dos } \\
\text { prodilos coletadis em } \\
\text { condiçóes de uso }\end{array}$ \\
\hline & 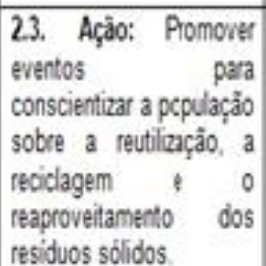 & $\begin{array}{l}\text { 2.3. Indicador Especifico: } \\
\text { Numero de eventos } \\
\text { realizado pelas escolas } \\
\text { anualmente para a } \\
\text { fnalidade }\end{array}$ & $\begin{array}{|lr|}\text { Dados } & \text { anuais } \\
\text { fomecidos } & \text { pelas } \\
\text { escolas } & \\
\end{array}$ & $\begin{array}{l}\text { Zero } \\
\text { evento } \\
\text { realizado }\end{array}$ & Contivuo & $\begin{array}{l}\text { 23. Mets especifica: } \\
\text { Realizar eventos timestrais } \\
\text { por ano para esta firalidada }\end{array}$ \\
\hline
\end{tabular}

c) Logística reversa

Será criado o programa "Na pilha". Este programa será coordenado pela Secretaria de Saúde e Meio Ambiente e terá como objetivo dar destino adequado às pilhas e baterias. A ação do programa será criar um acordo alguma empresa, instituto ou associação especializada em logística reversa de pilhas e baterias. A recomendação é que esse acordo seja feito com a Associação Brasileira de Indústria Elétrica e Eletrônica (ABINEE).

O programa "Na pilha" vai envolver a participação de comerciantes e empresários que comercializam pilhas e baterias. Pretende-se que o programa seja contínuo e sua meta é que em até dois anos após a implantação do programa, todas as pilhas e baterias já tenham destino adequado e conhecido pela comunidade local. 
Para cumprir a meta de implantação do programa de logística reversa é importante que a população tenha conhecimento da lei de logística reversa da política nacional de resíduos sólidos (PNRS). Galvão et al. (2016) afirmam que a falta de conhecimento da legislação e de informações sobre a destinação final adequada dos resíduos eletrônicos é um problema.

Gutierrez et al. (2017) fez um estudo sobre o descaso com lixo eletrônico na cidade de Belém do Pará e concluiu que a inexistência de projetos, de ações ecologicamente corretas ou qualquer trabalho direcionado especificamente para destinar corretamente o lixo eletroeletrônico por parte da prefeitura de Belém são fatores para o descaso de lixo eletrônico na capital da região amazônica. Neste sentido, é importante que o poder público de São Francisco seja sempre presente e atuante no programa de logística reversa. baterias.

A Tabela 3 ilustra o programa e a ação para logística reversa de pilhas e

Tabela 3: Programa e Açoes para logistica reversa de pilhas e baterias

\begin{tabular}{|c|c|c|c|c|c|c|}
\hline \multirow{2}{*}{$\begin{array}{l}1^{\prime} \text { Passo } \\
\text { Objetivos }\end{array}$} & \multirow{2}{*}{$\begin{array}{l}2^{2} \text { Passo } \\
\text { Programas e } \\
\text { Açees }\end{array}$} & \multicolumn{3}{|l|}{$3^{\prime}$ Passo } & \multicolumn{2}{|l|}{$4^{\circ}$ Passo } \\
\hline & & Indicadores & $\begin{array}{l}\text { Fonte da } \\
\text { Informação }\end{array}$ & Situaç̧o Atual & Prazo & Metas \\
\hline \multirow{2}{*}{$\begin{array}{l}\text { 3. Objetivos: } \\
\text { Descatar pilhas e } \\
\text { baterias } \\
\text { adequadamente. }\end{array}$} & $\begin{array}{l}\text { 3. Programas: "na } \\
\text { pilha" }\end{array}$ & $\begin{array}{l}\text { 3. Indicador Geral: } \\
\text { Numero de pilhas, } \\
\text { batenass e } \\
\text { embalagens de } \\
\text { agrotóxicos } \\
\text { coletadas. }\end{array}$ & $\begin{array}{l}\text { Dados fomecidos } \\
\text { pela Secretana de } \\
\text { Saide e Meio } \\
\text { Ambiente }\end{array}$ & & Continuo & $\begin{array}{l}\text { 3. Meta Geral: Dar } \\
\text { destino adequado a } \\
\text { 100\% das pihas e } \\
\text { batenasa até o final } \\
\text { co segundo ano de } \\
\text { execucuáa do } \\
\text { programa }\end{array}$ \\
\hline & $\begin{array}{l}\text { 3.1. Açäo: Aticular } \\
\text { com ABNEEE a } \\
\text { implantaç̧ẫo da } \\
\text { logistica reversa de } \\
\text { pilhas e batenas no } \\
\text { municipio }\end{array}$ & $\begin{array}{l}\text { 3.1. Indicador } \\
\text { Fspecifico: } \\
\text { Existência de termo } \\
\text { de compromisso }\end{array}$ & $\begin{array}{l}\text { Dados fomecidos } \\
\text { pela Secretania de } \\
\text { Saude e Meio } \\
\text { Ambiente }\end{array}$ & Acordos inexistentes & Cunto & $\begin{array}{l}\text { 3.1. Meta } \\
\text { Especifica: Termo } \\
\text { de compromisso } \\
\text { assinado até o } \\
\text { pimeiro ano de } \\
\text { implantação do } \\
\text { programa }\end{array}$ \\
\hline
\end{tabular}

d) Compostagem

O nome do programa para desenvolver a compostagem no município de São Francisco será "Pró-Compostagem", os objetivos do programa serão: fazer composteiras nas escolas e usá-las para educação das crianças e jovens das escolas, além de toda a comunidade; e usar o programa Pró-Compostagem para implantar agricultura sustentável na região.

O primeiro passo será a criação de composteiras com minhocas nas escolas. É importante que nessa etapa os professores motivem a participação 
efetiva dos alunos porque eles podem ser divulgadores do projeto e também ampliar esses conhecimentos, levando-os para seus familiares e pessoas do seu convívio. Além da educação, as instruções sobre "como fazer" e seguindo o exemplo de outras pessoas geralmente são as ferramentas mais eficazes para reduzir o desperdício (PINTO et al., 2018).

Em seguida, o projeto deverá ser divulgado para a comunidade. Gutiérrez-Barba e Ortega-Rubio (2013) mostraram em um estudo que a intervenção educativa como um workshop é uma boa estratégia para a prevenção do desperdício de alimentos e, provavelmente, preferível às taxas de resíduos, impostos ou multas.

Feito a divulgação e a população tendo conhecimento do programa "PróCompostagem", o próximo passo consiste na coleta de resíduos orgânicos e algumas minhocas para auxiliar na compostagem. Estes resíduos serão restos de comidas das escolas e doméstica. Feito a coleta dos resíduos orgânicos, eles serão colocados para passarem pelo processo. Depois que o processo de compostagem tiver sido concluído, o resultado será adubo orgânico. Este adubo poderá ser entregue para os agricultores locais realizarem agricultura sustentável.

A Tabela 4 mostra este programa e suas ações para compostagem.

Tabela 4: programas e açōes para compostagem.

\begin{tabular}{|c|c|c|c|c|c|c|}
\hline \multirow{2}{*}{$\begin{array}{l}1^{\circ} \text { Passo } \\
\text { Objetivos }\end{array}$} & \multirow{2}{*}{$\begin{array}{l}2^{\circ} \text { Passo } \\
\text { Programas e } \\
\text { Açóes }\end{array}$} & \multicolumn{3}{|l|}{$3^{\circ}$ Passo } & \multicolumn{2}{|l|}{$4^{\circ}$ Passo } \\
\hline & & Indicadores & $\begin{array}{l}\text { Fonte da } \\
\text { Informação }\end{array}$ & Situação Atual & Prazo & Metas \\
\hline \multirow[t]{3}{*}{$\begin{array}{l}\text { 4. Objetivos: criar } \\
\text { composteiras nas } \\
\text { escolas e } \\
\text { incentivar a } \\
\text { prática da } \\
\text { agricultura } \\
\text { orgânica na } \\
\text { região. }\end{array}$} & $\begin{array}{l}\text { 4. Programas: } \\
\text { "Pró- } \\
\text { Compostagem" }\end{array}$ & $\begin{array}{l}\text { 4. Indicador } \\
\text { Geral: Número de } \\
\text { agricultores } \\
\text { (familias) que } \\
\text { fazem } \\
\text { compostagem }\end{array}$ & $\begin{array}{l}\text { Dados anuais } \\
\text { fornecidos pela } \\
\text { Secretaria de } \\
\text { Meio Ambiente }\end{array}$ & $\begin{array}{l}\text { Nenhum agricultor } \\
\text { faz compostagem }\end{array}$ & Continuo & $\begin{array}{l}\text { 4. Meta Geral: } \\
\text { Adotar a atividade } \\
\text { de compostagem } \\
\text { em } 100 \% \text { dos } \\
\text { agricultores rurais } \\
\text { até o segundo ano } \\
\text { do programa }\end{array}$ \\
\hline & $\begin{array}{l}\text { 4.1. Ação: } \\
\text { Divulgar o } \\
\text { programa "Pró- } \\
\text { Compostagem" }\end{array}$ & $\begin{array}{l}\text { 4.1. Indicador } \\
\text { Específico: } \\
\text { Número de } \\
\text { eventos } \\
\text { realizados. }\end{array}$ & $\begin{array}{l}\text { Dados anuais } \\
\text { fornecidos pela } \\
\text { Secretaria de } \\
\text { Saúde e Meio } \\
\text { Ambiente }\end{array}$ & $\begin{array}{l}\text { Zero evento } \\
\text { divulgado }\end{array}$ & Curto & $\begin{array}{l}\text { 4.1. Meta } \\
\text { Especifica: } \\
\text { Promover eventos } \\
\text { trimestrais para } \\
\text { essa finalidade. }\end{array}$ \\
\hline & $\begin{array}{l}\text { 4.2. Ação: } \\
\text { Professores e } \\
\text { alunos vão fazer } \\
\text { as composteiras } \\
\text { nas escolas. }\end{array}$ & $\begin{array}{l}\text { 4.2. Indicador } \\
\text { Específico: } \\
\text { número de } \\
\text { composteiras nas } \\
\text { escolas. }\end{array}$ & $\begin{array}{l}\text { Dados anuais } \\
\text { fornecidos pela } \\
\text { Secretaria de } \\
\text { educação }\end{array}$ & $\begin{array}{l}\text { Nenhuma } \\
\text { composteira nas } \\
\text { escolas }\end{array}$ & Curto & $\begin{array}{l}\text { 4.2. Meta } \\
\text { Específica: fazer } \\
\text { uma composteira } \\
\text { em cada escola } \\
\text { do munícipio }\end{array}$ \\
\hline
\end{tabular}




\section{Conclusão}

Espera-se que os programas e as ações para serem implantados em São Francisco sejam aceitos, tendo como principal resultado esperado a resolução ou pelo menos a mitigação de problemas relacionados ao gerenciamento de resíduos sólidos do município. É importante que toda sociedade esteja envolvida na criação e participação dos programas e ações. Esses direcionamentos, se bem implantados, podem trazer melhorias para os ambientes escolares da cidade, que seria outro bom resultado para se almejar.

Nesse sentido, Park et al. (2011) afirmam que melhorar o ambiente interno da escola, utilizando elementos de design ecologicamente correto ao projetar a construção de prédios escolares e, ao mesmo tempo, uma direção para usar instalações ecologicamente corretas, são eficazes ferramentas para EA.

Assim, quando de fato os programas e as ações forem implantados pela prefeitura, que passe a trabalhar no desenvolvimento e melhora contínua dos programas e também havendo o trabalho junto às escolas e à população local espera-se um aumento no IDH do município visto que, num período de médio ou longo prazo, haja melhora na qualidade de vida para região e uma sociedade local mais sustentável.

Com relação aos programas e ações, o programa "São Francisco Mais Limpa" deve ser o programa mais difícil para ser implantado devido aos custos financeiros. Os demais programas serão implantados com mais facilidade por se tratarem de programas de baixo custo e que requerem apenas apoio popular.

\section{Referências}

BIERNACKI, P.; WALDORF, D. Snowball Sampling: Problems and techniques of Chain Referral Sampling. Sociological Methods \& Research, vol. № 2, 1981. p141-163.

BRASIL. Lei no. 9.795, de 27 de abril de 1999. Dispõe sobre a Educação Ambiental, institui a Política Nacional de Educação Ambiental e dá outras providências. Diário Oficial [da] República Federativa do Brasil, Brasília, Brasília, DF, 28 abr. 1999.

BRAUN,T; DIERKES,P. Evaluating Three Dimensions of Environmental Knowledge and Their Impact on Behaviour. Research in Science Education, Editora: Springer, 2017. p 1-19.

BRINGHENTI,J.R; GÜNTHER,W.M.R. Participação social em programas de coleta seletiva de resíduos sólidos urbanos. Revista Engenharia Sanitária e Ambiental, vol. 16, no 4 2011.p 421-430. 
CHAVES,R.A; GAIA,M.C.M. O papel da escola na construção da Educação Ambiental: ações e reflexões. Revista de Ensino de Biologia da SBEnBIO, Ed. 7, 2014. p 6356-6368.

GALVÃO, H.M; BRENZAN,R; OLIVEIRA, L.M. A logística reversa aplicada na política nacional de resíduos sólidos e na lei estadual paulista do resíduo tecnológico em Pindamonhangaba - SP. DIÁLOGO, Canoas, n.33, 2016. p 141-169.

GOVERNO DO ESTADO DE SÃO PAULO. Coleta Seletiva para Prefeituras, $4^{\circ}$ edição;

GUTIERREZ, C.B.B; GUTIERREZ, D.M.G; SANTOS, L.S;PONTES,A.N; RIBEIRO,H.M.C; MORALES,G.P. O descaso com o lixo eletroeletrônico de uma metrópole amazônica: o caso da cidade de Belém, Pará. Revista Espacios, Vol. 38, Ed.2, artigo número 12. 2017.

GUTIÉRREZ-BARBA, B.E.; ORTEGA-RUBIO, A. Household food-waste production and a proposal for its minimization in Mexico. Life Science Journal, Vol. 10,Ed. 3, 2013. p 1772-1783.

HEIDARI, F.; HEIDARI, M. Effectiveness ofManagement of Environmental Education on Improving Knowledge for Environmental Protection (Case Study: Teachers at Tehran's Elementary School). International Journal of Environmental Research, Vol. 9, Ed. 4, 2015. p 1225-1232.

IBGE. Panorama de São Francisco - PB. Disponível em: https://cidades.ibge.gov.br/brasil/pb/sao-francisco/panorama Acesso em: $18 \mathrm{de}$ Abril de 2018.

LIEFLÄNDER, A.K.; BORGNER, F.X. Educational impact on the relationship of environmental knowledge and atitudes. Environmental Education Research, Vol. 24, Ed. 4, 2018. p 611-624.

MADDOX, P.; DORRAN, C. ;WILLIAMS, I.D.; KUS, M. The role of intergenerational influence in waste education programmes: The THAW project.

Waste Management, vol. 31, ed. 12, 2011. p 2590-2600.

MINISTÉRIO DO MEIO AMBIENTE. Orientações para elaboração de Plano Simplificado de gestão Integrada de Resíduos Sólidos - PSGIRS para municípios com população inferior a 20 mil habitantes. $3^{\circ}$ edição. Brasília DF, 2016.

NOVO-CORTI I, GARCÍA-ÁLVAREZ MARÍTERESA, VARELA-CANDAMIO L. The importance of environmental education in the determinants of green behavior: A meta-analysis approach. Journal of Cleaner Production, vol. 170, 2018. p 1565-1578.

PARK, J.C. ;CHUNG, M.H. ;RHEE, E.K. Field Survey on the Indoor Environment of Elementary Schools for Planning of Environment Friendly School Facilities. Journal of Asian Architecture and Building Engineering, Vol. 10, Ed. 2, 2011. p 461-468. 
PINTO, R.S. ;PINTO, R.M.S. ;MELO, F.F.S.; CAMPOS, S.S., CORDOVIL, C.M.S. A simple awareness campaign to promote food waste reduction in a University canteen. Waste Management, editora: Elsevier, 2018. p 1-11.

POST,D.; MENG, Y. Does schooling foster environmental values and action? A cross-national study of priorities and behaviors. International Journal of Education Development, vol. 60, 2018. p 10-18.

PREFEITURA DE SÃO PAULO -SP. Composta São Paulo. São Paulo-SP. 2014. Disponível em: https://www.compostasaopaulo.eco.br/ acesso em: 10 de Abril de 2018.

SUPAKATA, N.; PUANGTHONGTHUB, S.; SRITHONGOUTHAI, S.; KANOKKANTAPONG, V.; CHAIKAEW, P. Environmental camp as a comprehensive communication tool to promote the RRR concept to elementary education students at Koh Si Chang School. Applied Environmental Education and Communication, Vol 14, Ed 2, 2016.p 184-194.

UNITED NATIONS DEVELOPMENT PROGRAMME.T able 1: Human
Development Index and its componentes. Disponível em:
http://hdr.undp.org/en/composite/HDI Acesso em: 18 de Abril de 2018.

ZIARI, K.; POURAHMAD, A.; FOTOUHI MEHRABANI, B.; HOSSEINI, A. Environmental sustainability in cities by biophilic city approach: a case study of Tehran. International Journal of Urban Sciences, 2018. p 1-31 